\title{
Water budget and its variation in Hutuo River basin predicted with the VIP ecohydrological model
}

\author{
FARONG HUANG ${ }^{1,2}$ \& XINGGUO MO \\ 1 Key Laboratory of Water Cycle \& Related Land Surface Processes, Institute of Geographical Sciences and Natural \\ Resources Research, Chinese Academy of Sciences, Beijing, 100101, China. \\ 2 University of Chinese Academy of Sciences, Beijing, 100049, China \\ moxg@,igsnrr.ac.cn
}

\begin{abstract}
Accurate assessment of water budgets is important to water resources management and sustainable development in catchments. Here the VIP (Vegetation Interface Processes) ecohydrological model is used to estimate the water budget and its influence factors in Hutuo River basin, China. The model runs from 1956 to 2010 with a spatial resolution of $1 \mathrm{~km}$, utilizing remotely sensed LAI data of MODIS. During the study period the canopy transpiration takes up 58\% of evapotranspiration over the whole catchment and the fractions of soil and interception evaporation are $36 \%$ and $6 \%$ respectively. The annual evapotranspiration and streamflow are both declining, mainly resulting from the decrease of annual precipitation. Attribution analysis shows that the contributions of climate change and human activities to the decrease of streamflow are $48 \%$ and $52 \%$, respectively.
\end{abstract}

Key words streamflow; evapotranspiration; Hai River Basin; VIP model; climate change; human activities

\section{INTRODUCTION}

In the past decades, the surface water of Hai River basin in north China has decreased steadily. It is important to assess the water budget, its long-term variation and impact factors for this area. Generally, climate change and human activities are the two main driving factors of hydrological processes. In recent years, a number of studies have been conducted to investigate the relative (Tang et al., 2014), individual (Nune et al., 2014; Qiao et al., 2014) and combined (Alaoui et al., 2014) impacts of these two factors all over the world. In Hai River basin, many researchers have identified and quantified the change of water budget and its driving factors with regression analysis (Yang and Tian, 2009), hydrological sensitivity analysis, the climate elasticity method, conceptual hydrological models (Wang et al., 2013) and semi-distributed hydrological models, such as Variable Infiltration Capacity (VIC) model (Bao et al., 2012) and Soil and Water Assessment Tool (SWAT) (Sun and Ren, 2013). However, the contributions of climate change and human activities are varied. Based on the comparison of correlation coefficients, agricultural water use is likely the main driving factor of runoff decline in Haihe River basin. While, based on the VIC model, climate variability is the major driving factor for the streamflow decrease in the Qinlong River catchment, which is one of the upstream sub-basins. The distributed physically based hydrological model may be a more acceptable choice for hydrological effect study (Legesse et al., 2003). In this paper, we employ the distributed VIP ecohydrological model to assess the water budget, its variation and driving factors from 1956 to 2010 for Hutuo River basin (HRB), which is one of the key parts of Hai River basin.

\section{STUDY AREA}

The HRB is a headwater mountainous sub-basin of Hai River basin, China, most of which belongs to Shanxi Province. Its average altitude is about $1300 \mathrm{~m}$, ranging from 361 to $3041 \mathrm{~m}$ (Fig. 1(a)). The drainage area for Xiaojue hydrological station is about $14000 \mathrm{~km}^{2}$, extending from latitude $38^{\circ} 01^{\prime}$ to $39^{\circ} 28^{\prime} \mathrm{N}$ and longitude $112^{\circ} 13^{\prime}$ to $113^{\circ} 58^{\prime} \mathrm{E}$. Most of the area is covered with grass (60.5\%) and crops (29.7\%; Fig. 1(d)). Maize, beans and potato are the dominant cultivated crops for the single-crop rotation system in this catchment. The two main soil types are sandy loam and loam, covering $45.8 \%$ and $53.5 \%$ of the catchment, respectively (Fig. 1(c)). The continental monsoon climate is prevalent in the study area, which is characterized with cold and dry winters and hot and rainy summers. The mean annual precipitation and runoff depth of the catchment are about 586 and $47 \mathrm{~mm}$, respectively. 


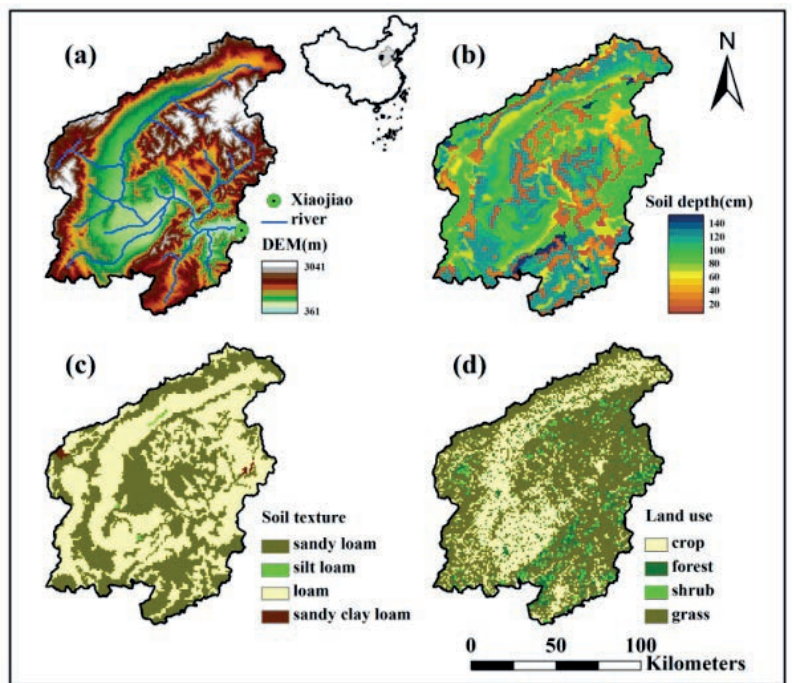

Fig. 1 The DEM (a), soil depth (b), soil texture (c) and land use (d) of HRB with Xiaojue hydrological station as outlet in Hai River basin (the grey area in the inserted map), China.

\section{METHOD AND MATERIAL}

\subsection{Model description}

The VIP ecohydrological model employed in this work has been successfully used to predict the water budget over the Lushi (Mo et al., 2005), Wudinghe (Mo et al., 2003) and Xitiao (Mo and Meng, 2011) river catchments. The runoff generation of VIP is simulated according to the variable infiltration capacity scheme, and the overland and channel runoff routing is computed based on the kinematic wave equation solved by a one-dimensional four point finite backward-difference method. The actual evapotranspiration (ET) of VIP is divided into three parts: the canopy transpiration (Ec), evaporation of soil (Es) and intercepted rainfall (Ei), which are calculated based on the water and energy balances. The soil water movement is described by a six-layer scheme, in which the first layer is the source of Es, the intermediate four layers are the source of root uptake for Ec, and the lowest one is the source of groundwater recharge (Mo et al., 2005). Moreover, soil depth data (Fig. 1(b)) from Wei et al. (2013) is used instead of the constant soil depth in the original VIP version.

\subsection{Data}

In this work, we utilize the daily minimum, maximum, and average temperature, precipitation, average wind speed, vapour pressure, sunshine hour and average atmospheric pressure data of 78 meteorological stations in and around the study area, provided by the China Meteorological Data Sharing Service System (http://cdc.cma.gov.cn), to derive the spatial patterns of these climate variables at 1-km spatial resolution with the inverse distance square method corrected by altitude. The remotely-sensed data used in this work is the leaf area index (LAI), derived from the MODIS NDVI product with a spatial resolution of $1 \mathrm{~km}$ and temporal resolution of 16 days, for the period 2001-2010, according to the method below (Carlson and Ripley, 1997),

$$
\mathrm{f}_{\mathrm{c}}=\frac{\mathrm{NDVI}-\mathrm{NDVI}_{\mathrm{o}}}{\mathrm{NDVI}_{\mathrm{m}}-\mathrm{NDVI}_{\mathrm{o}}}
$$

where $N D V I_{o}$ and $N D V I_{m}$ are the $N D V I$ values of bare soil surface and dense canopy, respectively. For relatively homogeneous canopies, there is an approximately exponential relationship between LAI and $f_{c}$, expressed as equation (2):

$$
L A I=-\frac{\ln \left(1-f_{c}\right)}{k_{\text {par }}}
$$

where $k_{p a r}$ is the canopy extinction coefficient of visible radiation. The 10-year LAI data are 
averaged to represent the vegetation characteristics in the period before 2001. The observed discharge data for the outlet station is got from the Annual Hydrological Report of China.

\subsection{Method to assess the attributions to streamflow change}

The hydrological cycle and water budget will change with the climate variability and anthropological activities. Here we use the VIP ecohydrological model and the method reported by Bao et al. (2012) to quantify the impact of climate variability and human activities on streamflow change. First, we need to identify the "natural period" and "impacted period" of annual streamflow time series. The sequential version of the Mann-Kendall test (Sneyers, 1975) is utilized to identify these two periods. Second, the change of annual streamflow $(\Delta Q)$ is calculated by equation (3),

$$
\Delta Q=Q_{o b n}-Q_{o b i}
$$

where $Q_{o b n}, Q_{o b i}$ are the observed average annual streamflow in the natural and impacted period. Third, the change caused by climate variability $\left(\Delta Q_{c}\right)$ is computed by the following equation,

$$
\Delta Q_{c}=Q_{\text {simn }}-Q_{\text {simi }}
$$

where $Q_{\text {simn }}, Q_{\text {simi }}$ are the reconstructed average annual streamflow by VIP in the natural and impacted period. Finally, to reduce the simulation uncertainty, we correct the original equation to separate the relative contribution of these two factors. The contribution of climate change $\left(\eta_{c}\right)$ and human activities $\left(\eta_{h}\right)$ to the annual streamflow change is acquired from equation (5):

$$
\eta_{c}=\frac{\Delta Q_{c} / Q_{\text {simn }}}{\Delta Q / Q_{o b n}}=1-\eta_{h}
$$

\section{MODEL VALIDATION}

We employ VIP over HRB at a spatial resolution of $1 \mathrm{~km}$ for 1956-2010, and compare the simulated and observed discharge at the monthly and annual time scale. It is found that the simulated monthly average discharge agrees well with the observed data before 1979, as shown in Fig. 2, with a Nash-Sutcliffe efficiency of 0.68 and Pearson correlation coefficient of 0.85 , while after 1979 the corresponding values are only 0.01 and 0.67 . According to the results reported by Wang et al. (2013), the Nash-Sutcliffe efficiency (correlation coefficient) of monthly runoff were $0.86(0.93)$ for the simulation period $(1961-1975)$ but $0.62(0.79)$ for the validation period (1976-1979); the corresponding values in the present paper are $0.58(0.84)$ and $0.67(0.87)$, respectively. Thus, the simulation performance of VIP is better during the validation period. Particularly, according to our calculation, from 1956 to 1960, the correlation coefficient and NashSutcliffe efficiency of monthly streamflow can reach 0.88 and 0.77 , with a volume error of $6 \%$. Moreover, from 1956 to 2010 the correlation coefficient of annual runoff depth is 0.92 . Thus, the model efficiency is favourable.

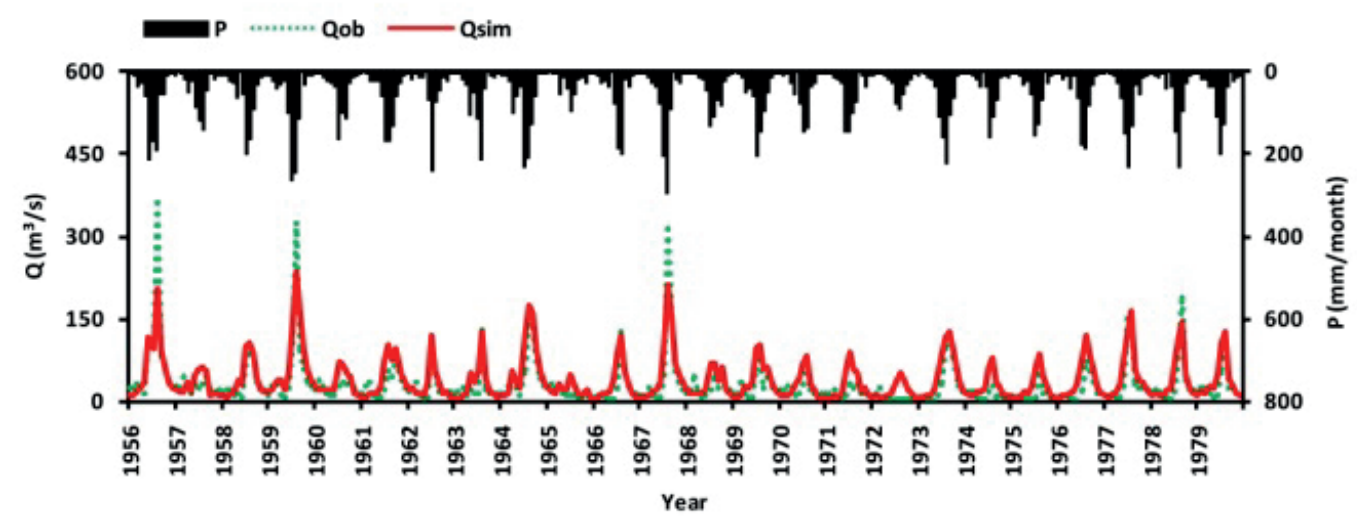

Fig. 2 The simulated and observed monthly average discharge of Xiaojue from 1956 to 1979 . 


\section{RESULTS}

\subsection{Trend of water budget and runoff coefficient}

The variation of the water budget is investigated based on linear regression. The linear trend of the annual water budget from 1956 to 2010 for the whole study area and each vegetation type is shown in Fig. 3 and Table 1. First, it is found that over the whole catchment Ec takes up 58\% of ET and the proportions of Es and Ei are 36\% and 6\% respectively. The decrease of ET and its components is significant (the linear trend passes the significance test at 5\% level), and the decline rate of Es and Ec are larger than that of Ei. Based on our calculation, for each land-use type and the whole catchment, the annual precipitation and ET both decreased obviously during the last 55 years. However, the decrease rate of annual precipitation for forest, shrub and grass is greater than that for crop. While the decline rate of ET for crop is larger, considering that the decrease rate of Ec for crop is larger than that for other land use types. For Ec, the trend is significant except for shrub and grass. Moreover, the variation of annual surface flow for the whole study area and each vegetation type is not significant. Nevertheless, the observed and simulated annual runoff coefficients both decline remarkably during the past five and a half decades (Fig. 4). Furthermore, the decline rate of the observed runoff coefficient is larger. It implies that besides climate change, human activities have affected the water budget from 1956 to 2010, and in the following we explore the effect of these two factors on the streamflow variation.

Table 1 Linear trends of water budget ( $\mathrm{mm} /$ year) for each vegetation type.

\begin{tabular}{lllll}
\hline & P & ET & Ec & Surface flow \\
\hline Crop & $-2.76^{*}$ & $-2.37^{*}$ & $-1.71^{*}$ & -0.02 \\
Shrub & $-3.73^{*}$ & $-1.57^{*}$ & -0.54 & -0.08 \\
Grass & $-3.36^{*}$ & $-1.37^{*}$ & -0.57 & -0.08 \\
Forest & $-3.48^{*}$ & $-2.15^{*}$ & $-1.27^{*}$ & -0.06 \\
\hline
\end{tabular}

* means significant change.

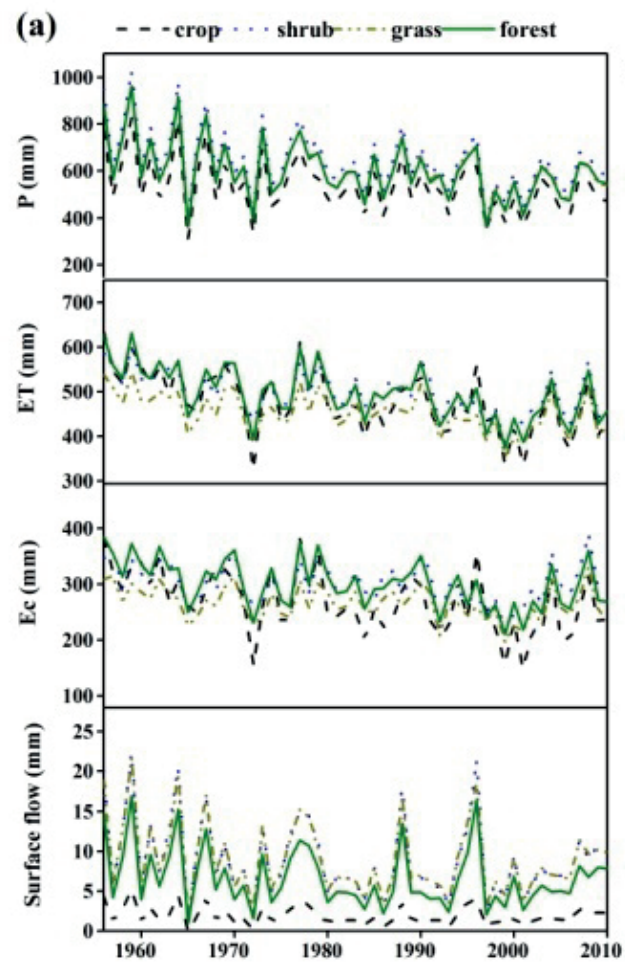

(b)

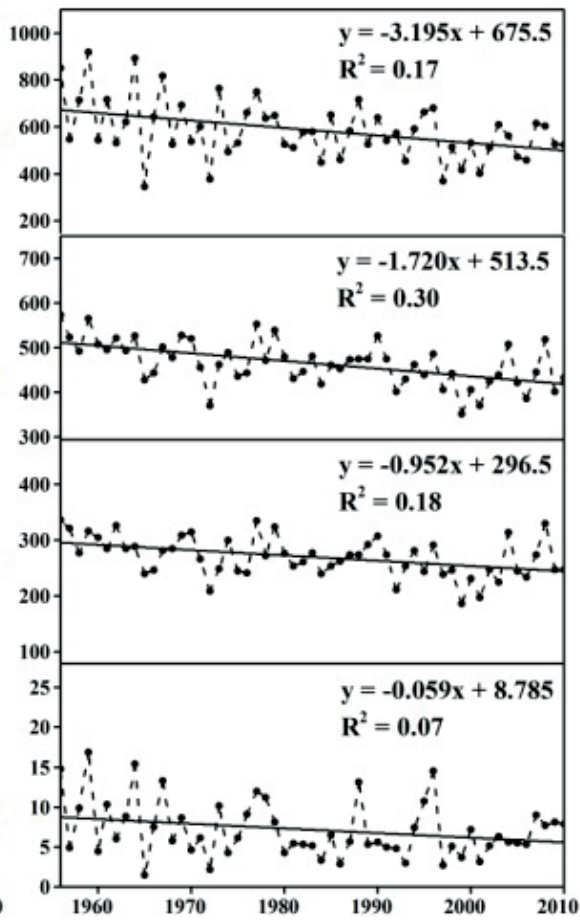

Fig. 3 The variations of annual precipitation (P), ET, Ec and surface flow for 1956-2010. (a) is for each vegetation type, and (b) for the whole catchment. 


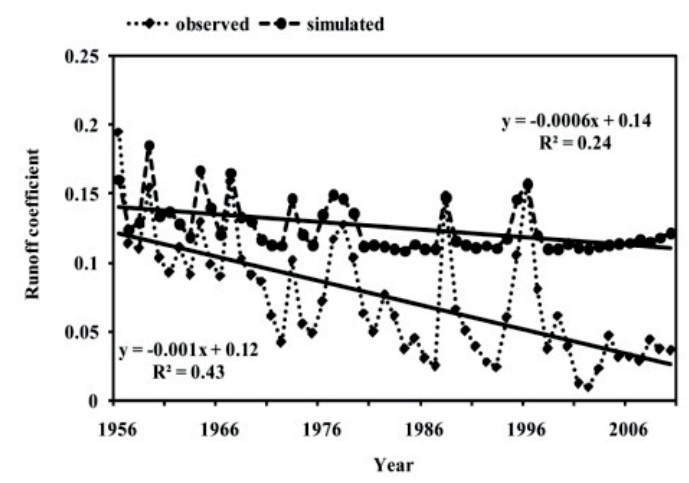

Fig. 4 The variation of runoff coefficient during the period of 1956-2010.

\subsection{Impact factors of streamflow change}

Based on the Mann-Kendall test there is an abrupt change of annual streamflow in 1979, as shown in Fig. 5 (right). This is in accordance with the result of Yang and Tian (2009). Thus, the period from 1956 to 1979 is the natural period and that after 1979 is the impacted period. According to our calculation, the relative change of annual streamflow $\left(\Delta Q / Q_{o b n}\right)$ is about $58 \%$, and the relative change caused by climate variability $\left(\Delta Q_{d} / Q_{s i m n}\right)$ is $28 \%$. Thus, the contributions of climate change and human activities to streamflow decrease during the study period are $48 \%$ and $52 \%$, respectively. It indicates that the effects of these two driving factors are comparable. It is found that, except for 1959, the annual precipitation of the area is always declining and has an abrupt change approximately in 1979, as shown in Fig. 5 (left). The abrupt change-point of annual precipitation is similar to that of runoff. Moreover, the annual precipitation and ET during the impacted period has decreased by $15 \%$ and $10 \%$ respectively, compared with that in the natural period. It implies the ET decrease caused by climate change is about $10 \%$. Further, the correlation coefficient between annual precipitation and observed streamflow in the natural period (0.87) is greater than that in the impacted period (0.64), and the mean observed runoff coefficient in the former period $(0.10)$ is larger than that in the latter $(0.05)$. Thus, the observed annual streamflow is related more closely to the annual precipitation in the natural period and under similar annual precipitation the annual streamflow for the impacted period is less.
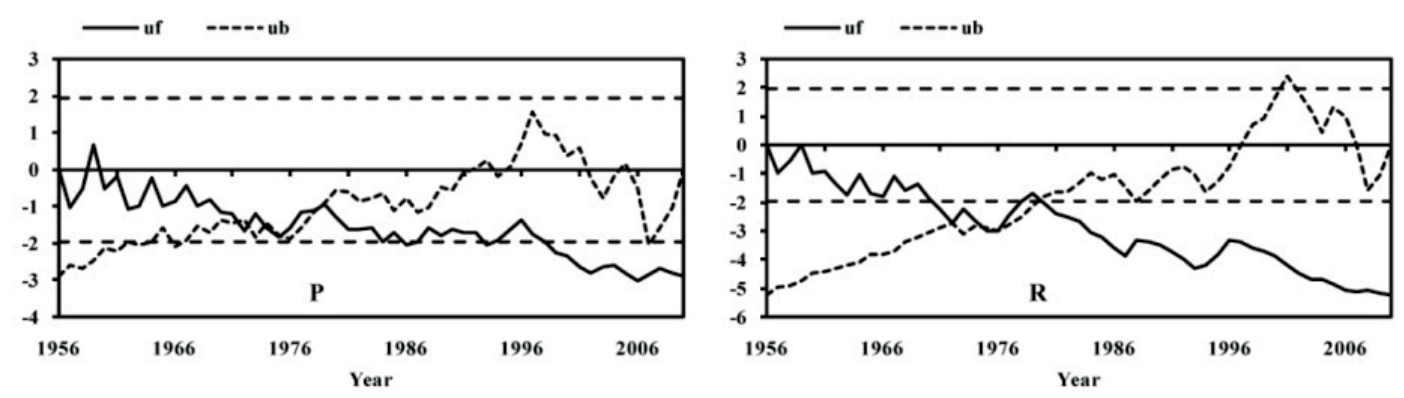

Fig. 5 Mann-Kendall's testing statistics values of annual precipitation $(\mathrm{P})$ and observed annual streamflow $(\mathrm{R})$ for the whole study area (1956-2010). uf indicates the forward trend, and ub the backward trend.

\subsection{Simulation uncertainties}

Though the performance of the VIP model in this work is favourable, there are still some shortcomings. First, during the whole study period 1956-2010, it is found that the capability of the VIP ecohydrological model to simulate monthly discharge during the flood season is not strong in wet and dry years. During the natural period, in the dry years, such as 1961, 1965, 1971, 1972, 1974, 1975 and 1976, the peak value of monthly discharge is overestimated, and in the wet years, such as 1959 , the peak value of monthly discharge is underestimated, thus the observed and 
simulated runoff coefficients differ much from each other. During the impacted period, most of the observed runoff coefficients are much smaller than the simulated ones, implying there may be water withdrawal from river, which should be studied further. Moreover, the averaged 2001-2010 LAI data is used in the period before 2001. To evaluate the simulation uncertainties caused by this kind of substitution, we use LAI data of the years (during 2001-2010) with the maximum and minimum annual mean LAI to drive VIP for 1956-2000, respectively. It is found that during 1956-2000, compared to the result forced by the averaged 2001-2010 LAI data, the relative errors of mean annual ET and runoff depth for these two kinds of LAI data are both less than 5\%.

\section{CONCLUSION}

In this paper, we employ a distributed ecohydrological process-based model (VIP) to predict the water budget, its variation and impact factors in HRB of Haihe River basin from 1956 to 2010. It is found that during the study period Ec takes up 58\% of ET for the whole catchment, and the proportions of Es and Ei are 36\% and 6\%, respectively. For each land use type and the whole area, the decrease of annual precipitation and evapotranspiration is significant, but the decline rate of precipitation is larger. The runoff coefficients also fall remarkably during the period from 1956 to 2010, while the decrease rate for the observed item is greater. Furthermore, during the study period, the contribution of climate variability and human activities to streamflow decrease are comparable.

Acknowledgements This study is supported by the "135" strategic Science and Technology plan of Institute of Geographical Sciences and Natural Resources Research, Chinese Academy of Sciences (No. 2012ZD003) and grant from Natural Science Foundation of China (40471026).

\section{REFERENCES}

Alaoui, A., et al. (2014) Modelling the effects of land use and climate changes on hydrology in the Ursern Valley, Switzerland. Hydrological Processes 28, 3602-3614.

Bao, Z., et al. (2012) Attribution for decreasing streamflow of the Haihe River basin, northern China: Climate variability or human activities? Journal of Hydrology 460-461, 117-129.

Carlson, T.N. and Ripley, A.J. (1997) On the relationship between fractional vegetation cover, leaf area index and NDVI. Remote Sensing of Environment 62, 241-252.

Legesse, D., Vallet-Coulomb, C. and Gasse, F. (2003). Hydrological response of a catchment to climate and land use changes in tropical Africa: case study South Central Ethiopia. Journal of Hydrology, 275(1-2), 67-85.

Mo, X. and Meng D. (2011) Simulation of the impacts of climate change on the water budget of the Xitiao River catchment, China. In: S. W. Franks (ed.) Hydro-Climatology: Variability and Change. IAHS Publ. 344, 150-156.

Mo, X., et al. (2003) Prediction of evapotranspiration and streamflow with a distributed model over the large Wuding River basin. In: Y. Tachikawa, ed. Weather Radar Information and Distributed Hydrological Modelling. IAHS Publ.282, 301-307.

Mo, X., et al. (2005) Long-term water budget estimation with the modified distributed model-LISFLOOD-WB over the Lushi basin, China. Meteorology and Atmospheric Physics 90(1-2), 1-16.

Nune, R., et al. (2014) Relating trends in streamflow to anthropogenic influences: a case study of Himayat Sagar catchment, India. Water Resources Management 28(6), 1579-1595.

Qiao, L., et al. (2014) Climate change and hydrological response in the trans-state Oologah Lake watershed: Evaluating dynamically downscaled NARCCAP and statistically downscaled CMIP3 simulations with VIC model. Water Resources Manage. 28(10), 3291-3305.

Sneyers, R. (1975) Sur l'analyse statistique des séries d'observations. WMO Tech Note.

Sun, C. and Ren, L. (2013) Assessment of surface water resources and evapotranspiration in the Haihe River basin of China using SWAT model. Hydrological Processes, 27(8), 1200-1222.

Tang, J., et al. (2014). Assessment of contributions of climatic variation and human activities to streamflow changes in the Lancang River, China. Water Resources Management 28(10), 2953-2966.

Wang, W., et al. (2013) Quantitative assessment of the impact of climate variability and human activities on runoff changes: a case study in four catchments of the Haihe River basin, China. Hydrological Processes 27(8), 1158-1174.

Wei, S., et al. (2013) A China data set of soil properties for land surface modeling. Journal of Advances in Modeling Earth Systems 5(2), 212-224.

Yang, Y. and Tian, F. (2009) Abrupt change of runoff and its major driving factors in Haihe River Catchment, China. Journal of Hydrology 374(3-4), 373-383. 